\title{
Infection Control Hospital Epidemiology
}

Volume 41, No S1

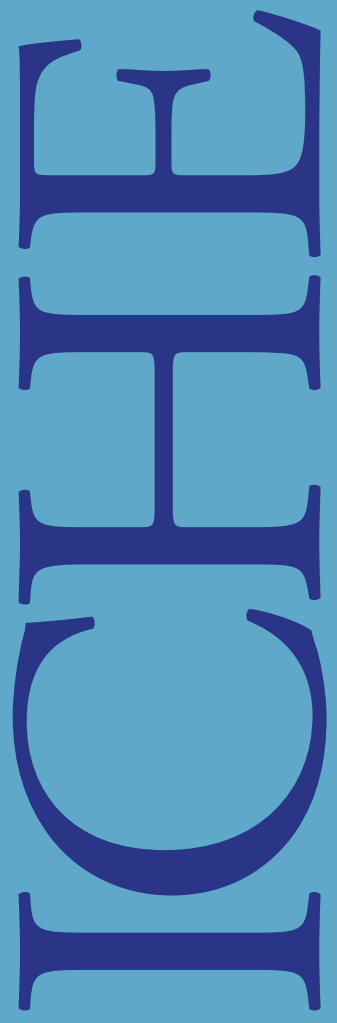

The Sixth Decennial International Conference on Healthcare Associated Infections Abstracts, March 2020

Global Solutions to Antibiotic Resistance in Healthcare SIR JOHN PRINGLE 


\section{Medicine \\ Books and Journals from Cambridge University Press}

The Cambridge Medicine programme focuses its book publishing in a defined set of core clinical areas with our great strength in the clinical brain sciences. Other specialties of significant focus include reproductive medicine/obstetrics and gynaecology, anaesthesia and critical care, emergency medicine and pathology.

Our journals programme covers a broad spectrum of medical disciplines including emergency and disaster medicine, epidemiology and infectious diseases, biomedical science, genetics, nutrition, mental health and psychiatry, and neuroscience.

We partner with many learned societies including The Society for Healthcare Epidemiology of America, the Neuroscience Education Institute, and the Royal College of Obstetricians and Gynaecologists.

For further details visit:

cambridge.org/core-medicine 
Volume 41 The Sixth Decennial International Conference on Healthcare-Associated Infections Abstracts, March $2020 \quad$ Number S1 Global Solutions to Antibiotic Resistance in Healthcare

\section{CONTENTS}

\section{Introduction}

S1 The Sixth Decennial International Conference on Healthcare-Associated Infections Abstracts, March 2020

Abstracts

S2 Top Oral Awards

S6 Distinguished Oral Abstracts

S16 Late Breaker Oral Abstracts

S20 Oral Presentations

S58 Top Rated Poster Presentations

S84 Late Breaker Poster Presentations

S87 Poster Presentations 


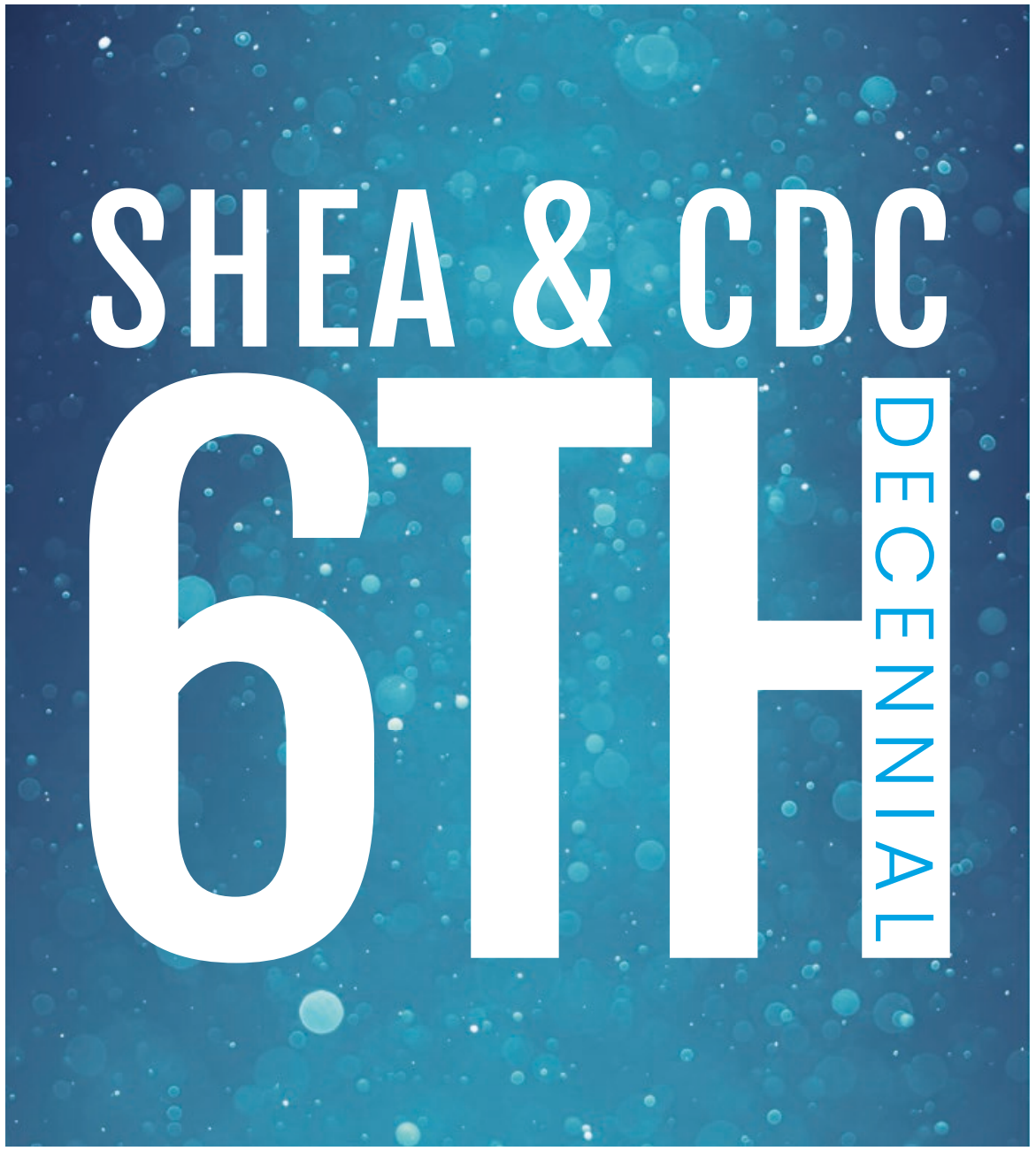

Advocates for prevention for more than 30 years.

Special Pathogens Laboratory provides proactive evidence-based solutions:

Legionella \& waterborne pathogens testing

\section{Water management services}

\section{Education}

\begin{tabular}{l|l} 
SPECIAL & THE
\end{tabular}

PATHOGENS LEGIONELLA

LABORATORY ${ }^{\circ}$ EXPERTS

specialpathogenslab.com 